\title{
La utópica protección del código PEGI
}

\author{
Ma Ángeles DíEz SÁNCHEZ \\ Universidad de Salamanca \\ madiez@usal.es \\ Ángeles LlorCa DíEZ \\ Universidad de Salamanca \\ tanamanca@hotmail.com
Gloria María BUENO CARRERA
Universidad de Salamanca
gloriabueno@usal.es
Beatriz CABREJAs MARTÍNEZ
Universidad de Salamanca
cmbea79@usal.es \\ Teresa Gallego Álvarez \\ Universidad de Salamanca \\ gallego.tr@usal.es
}

Recibido: 08/11/2012

Aceptado: 23/01/2013

\section{Resumen}

En 2003 en Europa se establece un código de autorregulación para los videojuegos (VJs) que se denominó Pan European Game Information (PEGI). El presente estudio se propone iinvestigar si dicha información ha llegado a los padres y/o tutores de menores de edad y lo utilizan como medida de protección. La muestra está compuesta por 403 progenitores, con media de edad de 45,94 años ( $\mathrm{Dt}=4,8)$. Se pone de manifiesto que a los adultos no les llega correctamente la información, detectan la edad pero no saben que está en relación con los descriptores de contenidos. El desconocimiento de los adultos, que ya se denuncia en los medios de comunicación, podría deberse a que los símbolos no sean los adecuados o que la población no interpreta las imágenes.

Palabras clave: videojuegos, menores, código PEGI.

\section{The Utopian Protection of the PEGI Code}

\begin{abstract}
In 2003, Europe has set up a self- regulatory code for Games, which was called Pan European Game Information (PEGI). This study aimed to investigate whether this information has come to parents and / or guardians of minors and if they use it like a measurement of protection. The sample consisted of 403 parents. The mean ages of the participants was 45,94 years $(\mathrm{SD}=4,8)$. In conclusion, it becomes clear that adults do not get the correct information, detect age but they do not know who is related to the content descriptors. Ignorance of adults, which is reported in the media, could be due to the inadequacy of symbols or because people cannot interpret the images.
\end{abstract}

Keywords: Videogames, minors, The PEGI System.

\section{Referencia normalizada}

DÍEZ SÁNCHEZ, Ma Ángeles; LLORCA DÍEZ, Ángeles; BUENO CARRERA, Gloria Ma; CABREJAS MARTÍNEZ, Beatriz; y GALLEGO ÁLVAREZ, Teresa (2013): "La utópica protección del código PEGI". Estudios sobre el Mensaje Periodístico. Vol. 19, Núm. especial abril, págs.: 711-723. Madrid, Ser-vicio de Publicaciones de la Universidad Complutense.

Sumario: 1. Introducción. 2. El código PEGI. 3. Difusión en los medios de comunicación. 4. Diseño y resultados de la investigación; 4.1. Metodología. 5. Referencias bibliográficas. 


\section{Introducción}

En octubre de 1997 nace en España la Asociación Española de Distribuidores y Editores de Software de Entretenimiento (aDeSe), que es la patronal del sector de los videojuegos (VJs), en nuestro país. Actualmente, forman parte de aDeSe doce compañías que representan más de un $80 \%$ del mercado español: Acclaim, Atari, Electronic Arts, FX Interactive, Microsoft, Nokia, Planeta De Agostini Interactive, Proein, Sony, Ubi Soft, Virgin Play y Vivendi Universal Publishing. Todas ellas, tienen como objetivos fundamentales el desarrollo de la industria del software de entretenimiento, la defensa de los intereses de sus asociados, así como el establecimiento de relaciones y colaboraciones con el fin de incrementar la incorporación de nuevos miembros, asociaciones y confederaciones, tanto nacionales como extranjeras. Entre sus proyectos destacan el fomento del desarrollo local de la industria, promocionando acuerdos con universidades y escuelas que desarrollen planes de estudio dirigidos al sector profesional y la continuación y potenciación de la lucha contra la piratería (Adese, 2004).

El importante papel que ejerce esta asociación no es tan sólo a nivel empresarial sino también liderar la iniciativa europea para establecer un nuevo sistema de clasificación de videojuegos por edades y contenidos PEGI (Información Paneuropea sobre Juegos). Otro organismo de gran trascendencia en establecer un sistema o código para regular los videojuegos fue el ISFE (Federación Europea del Software Interactivo); fundada en 1998 y registrada en 2002 conforme a la ley belga como una asociación internacional con fines científicos y pedagógicos. La ISFE representa los intereses del sector del software interactivo en los 27 Estados Miembro de la UE, además de Noruega, Islandia, Suiza y Liechtenstein. En la actualidad, los integrantes de la ISFE incluyen a 13 importantes fabricantes de software interactivo y 13 asociaciones profesionales de software interactivo de toda Europa.

Otro organismo implicado a nivel europeo es el Instituto Holandés de Clasificación de Medios Audiovisuales (NICAM); se trata de uno de los dos organismos independientes que administran el sistema en nombre de PEGI. Entre sus tareas se encuentran la revisión de los juegos de nivel 3 y 7 con arreglo a los criterios de PEGI, formación, archivo de juegos PEGI y la concesión de licencias PEGI (www.nicam.cc); el otro es el Video Standards Council (VSC), segundo administrador de PEGI que tiene su sede en el Reino Unido y que revisa los juegos para edades superiores.

El facilitar un código de autorregulación, era sumamente importante si se tienen en cuenta los datos que facilita aDeSe, con respecto a la industria de videojuegos, sector que aumenta anualmente su facturación en nueve de los principales mercados europeos, ascendiendo su recaudación desde 7.300 millones de euros el año 2007 a un total de 9.820 en el 2011, todo ello en pleno periodo de crisis, superando así a otros tipos de entretenimiento que hasta ahora lideraban tradicionalmente el mercado del ocio (aDeSe, 2011). Estas cifras abarcan el mercado de venta física de consolas y videojuegos (excluidos periféricos); el país que lidera el ranking es Reino Unido, seguido de Alemania y Francia.

\section{EI código PEGI}

En 2003 se estableció un Código de Conducta de la Industria de Software Interactivo de Europa sobre clasificación y etiquetado por edades, promoción y publicidad de los 
productos de software interactivo, que reemplazó otros existentes en 16 países de Europa, y por el que la industria se comprometía a informar sobre el contenido de estos productos y servicios de una forma objetiva, comprensible y responsable, se denominó sistema de la Información Paneuropea sobre Juegos (PEGI, Pan European Game Information) (www.pegi.info). Actualmente se utiliza en la mayor parte de Europa, en 30 países (Austria, Dinamarca, Hungría, Letonia, Noruega, Eslovenia, Bélgica, Estonia, Islandia, Lituania, Polonia, España, Bulgaria, Finlandia, Irlanda, Luxemburgo, Portugal, Suecia, Chipre, Francia, Israel, Malta, Rumanía, Suiza, República Checa, Grecia, Italia, Países Bajos, República Eslovaca y Reino Unido). Además, está respaldado por los principales fabricantes de consolas, incluidos Sony, Microsoft y Nintendo, así como por editores de juegos interactivos de toda Europa (aDeSe, 2004).

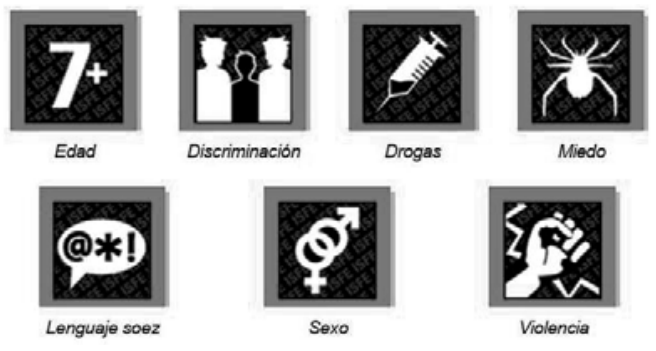

Fig. 1.: Edades y descriptores del código PEGI

Esta regulación, se divide en dos segmentos, la edad y una indicación del contenido del juego. El grado de la edad aparecería visible en la portada y permitirá a los compradores saber para qué edad está recomendado el título, la meta final sería orientar a los consumidores (especialmente a los padres, profesores y/o tutores) y ayudarles a tomar la decisión sobre si deben comprar o no un producto concreto. Así pues, la clasificación tiene en cuenta la idoneidad de la edad del consumidor y no su nivel de dificultad. El sistema PEGI incluye cinco categorías cómo mayores de tres, siete, doce, dieciséis y dieciocho años (Fig. 1).

" Mayores de 3 años: se supone que el contenido es apto para todas las edades. Se acepta cierto grado de violencia, pero dentro de un contexto cómico, que en general se corresponde con escenas agresivas típicas de dibujos animados, pues se supone que los menores no van a relacionar los personajes o situaciones de la pantalla con análogas circunstancias en la vida real. Tampoco, los videojuegos incluidos y aceptados para este grupo van a contener ni imágenes, ni sonidos que puedan asustar a los pequeños, ni utilizar lenguaje soez, ni hacer referencia a ninguna actividad sexual.

» Mayores de 7 años: cumple con todas las características incluidas en el apartado anterior, excepto que entre sus escenas o sonidos puede haber algunas que pueden causar miedo y se les permiten escenas con desnudo parcial.

» Mayores de 12 años: se pude mostrar una violencia ajena a dibujos animados, de una naturaleza ya sea de aspecto humano o con animales reconocibles. Puede contener desnudos, lenguaje soez suave, aunque no deben contener palabrotas relacionadas con la sexualidad. 
» Mayores de 16 años: los contenidos violentos o de actividad sexual pueden alcanzar un nivel similar a la vida real. Pueden contener lenguaje soez, incluir imágenes de consumo de tabaco y drogas y representar actividades delictivas.

» Mayores de 18 años: el nivel de violencia que pueden contener, puede alcanzar tal grado de brutalidad, que existe riesgo de producir repugnancia en el espectador.

» En cuanto a los contenidos se incorporan descriptores que aparecen en el reverso de los estuches indicando los motivos principales por los que un juego ha obtenido una categoría de edad concreta. Existen ocho descriptores: violencia, lenguaje soez, miedo, drogas, sexo, discriminación, juego y juego en línea con otras personas.

La clasificación ha ido evolucionando y desde 2007 aDeSe promueve la incorporación del PEGI Online (POSC) en las webs españolas de videojuegos. PEGI Online es un complemento del actual sistema de clasificación por edades PEGI, especialmente adaptado a las necesidades de protección de menores para el juego en línea. Al igual que el PEGI convencional, PEGI Online ha sido desarrollado por ISFE y NICAM, y cuenta con el auspicio de la Comisión Europea, como sistema de regulación de contenidos para el juego en línea. El logotipo de PEGI Online, que aparece en los estuches del juego si éste se vende en CD / DVD o en el propio sitio web del juego, indicará si puede jugarse en línea y, asimismo, si ese juego o sitio concreto es controlado por un operador que se ocupa de proteger a los jóvenes (Adese, 2007). El sistema PEGI tiene la interesante ventaja de ser voluntario y que las clasificaciones se establecen desde la propia industria de los videojuegos, a través de un cuestionario cumplimentado sobre los contenidos del mismo;

El equivalente americano del europeo es el Entertainment Software Rating Board (ESRB), realiza una clasificación semejante que también se divide en dos secciones: por una parte la edad adecuada para el juego, desde el punto de vista del contenido y no de su dificultad, y por otra, los elementos que han motivado la clasificación (INTECO, aDeSe, 2010). Así, elaboran las siguientes categorías:

- EC (Early Childhood): apto para mayores de tres años, no contienen material inapropiado para estas edades.

- E (Everyone): apto para mayores de 6 años, pueden contener violencia mínima en forma de dibujos animados, de fantasía.

- E10+ (Everyone Ten and Older): apto para mayores de 10 años, pudiendo contener violencia ligera no sólo en dibujos animados y fantasia, lenguaje algo elevado y temas minimamente provocativos.

- T (Teen): apto para mayores de 13 años, pudiendo contener violencia, temas insinuantes, humor grosero, escenas minimamente sangrientas, apuestas simuladas y uso poco frecuente de lenguaje soez.

- M (Mature): apto para mayores de 17 años, pueden contener violencia intensa, sangre y escenas sangrientas, contenido sexual y lenguaje soez.

- AO (Adults Only): solo apto para personas mayores de 18 años, pueden contener escenas prolongadas de violencia intensa, contenidos sexuales gráficos y desnudez.

- RP (Rating Pending): pendiente de clasificar

El equivalente japonés se denomina Computer Entertainment Rating Organization (CERO), importante si se tiene en cuenta que es precisamente el país asiático el que 
tradicionalmente es uno de las principales industrias en el desarrollo de los videojuegos. También clasifica los videojuegos con niveles e informan al consumidor acerca de la naturaleza del producto y para qué grupo de edad es adecuado. Fue establecido en julio de 2002, usando la ESRB norteamericana como modelo (Fig. 2):

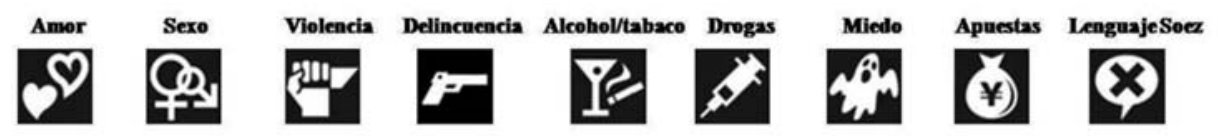

Fig. 2.: Computer Entertainment Rating Organization (CERO)

\section{Difusión en los medios de comunicación}

En España el código PEGI está avalado no sólo por aDeSe, sino también por diferentes instituciones públicas como el Ministerio de Sanidad y Consumo o el Defensor del Menor de la Comunidad de Madrid. Según los términos del acuerdo firmado con el Instituto Nacional de Consumo, aDeSe se comprometió a informar del código a los diferentes sectores afectados (padres, asociaciones, plataformas de la infancia y juventud) y a promocionarlo de forma que pudiese ser conocido adecuadamente por los destinatarios del mismo. El Convenio de colaboración firmado por aDeSe y el Defensor del Menor propició la incorporación de este último al Comité de Seguimiento del Sistema PEGI, donde comparte presencia activa con el Instituto Nacional del Consumo (Ministerio de Sanidad y Consumo) y con las instituciones correspondientes de las distintas Comunidades Autónomas, ya que la implantación del Código es universal. En virtud del convenio, entonces firmado, aDeSe se comprometía a facilitar el adecuado cauce participativo en el sistema a los sectores sociales, en especial padres, asociaciones y plataformas de la infancia y la juventud.

Por su parte, el Instituto Nacional del Consumo apoyó la difusión del material de información acerca del código PEGI mediante sus propios canales de distribución, contribuyendo a la financiación de la campaña de transmisión. En el marco de la campaña de difusión del PEGI, aDeSe firmó en el mes de octubre de 2003, un convenio con las revistas especializadas en videojuegos de las editoriales Grupo Zeta, Hobby Press y MC Ediciones, que se comprometieron a incluir de forma clara la edad del usuario recomendada en el etiquetado del videojuego y a divulgar y difundir información sobre el código mediante la inserción de publicidad gratuita. Por otra parte, aDeSe también llegó a un acuerdo de colaboración con canales de distribución, concretamente con Blockbuster, Carrefour, Centromail, El Corte Inglés, MediaMarkt, PC City y Toys"r"us; cada uno, apoyaría la difusión de los carteles y folletos de información sobre PEGI editados por aDeSe, poniéndolos a disposición de los consumidores en sus espacios de venta de videojuegos.

Es interesante a este respecto, el que se haya logrado que la industria posea autocontrol y sea un sector responsable en materia publicitaria. En este sentido ya han sido clasificados como positivos (no se aprecian inconvenientes al contenido) un total de 332; con modificaciones (se recomiendan hacer cambios) solamente 12; y negativos (se desaconseja la emisión del anuncio) tan sólo 1 (Adese, 2009). Es decir, la aceptación, implicación y respeto de la industria de los videojuegos por el Código PEGI, tras nueve años, sigue siendo muy alta, positiva y generalizada. 
Ahora bien, si se hace un brevísimo análisis de la distribución a los Medios de Comunicación de información sobre el Código, de forma que llegue al mayor porcentaje de consumidores, en especial a padres, tutores y/o profesores, se puede comprobar que el esfuerzo de difusión es muy intenso en los momentos iníciales. Sirva como ejemplo la nota de prensa "España adopta un nuevo código europeo de autorregulación para los videojuegos" que el Ministerio de Sanidad, Servicios Sociales e Igualdad, emite el 3 de junio de 2003:

.../ La Ministra de Sanidad y Consumo, Ana Pastor, ha presentado, hoy, el nuevo código europeo de autorregulación de los videojuegos, que supone una ampliación del creado en abril de 2001 por la Asociación Española de Distribuidores y Editores de Software de Entretenimiento (aDeSe).../

Se explicaba la clasificación por edad y los iconos descriptores, además se resaltaba que el nuevo código, auspiciado por la Comisión Europea, era objeto de un decidido empeño de la Presidencia Española de la Unión Europea (UE) durante el primer semestre de 2002.

Desde entonces, en los medios de comunicación han aparecido noticias sobre el código, con distintos motivos, así Elena Avellaneda (2003), en el diario El País, resaltaba en el titular "El videojuego se protege de la censura con códigos éticos de autorregulación":

/...Paralelamente al aumento de la afición crece la preocupación de los padres por el contenido de unos juegos en los que sus hijos pasan horas y horas. A pesar de que tan sólo un $13,2 \%$ de los juegos editados se catalogaron para adultos el pasado año, aumenta el recelo de los padres frente a los videojuego. De nada valen los estudios que periódicamente se difunden en donde no sólo no se demuestra la conexión entre videoadictos y conductas asociales, sino que alaban sus virtudes. Pese a ello, antes de que las cosas puedan complicarse y que el Gobierno tenga la tentación de legislar, la industria del entretenimiento electrónico se aplica su propio código de autorregulación. Es un sistema que advierte a qué tipo de público va dirigido el título.../

Un año después, aparece una interesante información con ocasión del convenio realizado con el Defensor del Menor de Madrid $(A B C, 2004)$ :

El Defensor del Menor de la Comunidad de Madrid, Pedro Núñez Morgades, y la Asociación Española de Distribuidores y Editores de Software de Entretenimiento (ADESE) firmaron ayer un convenio destinado a crear y promover un etiquetado responsable de los videojuegos, según informa Efe. El acuerdo, dentro del marco del Código PEGI para clasificación de contenidos, pretende facilitar a los padres y a los propios menores una referencia clara de los posibles contenidos perjudiciales para el desarrollo de los niños.../

Es en el año 2007 cuando el Instituto Nacional del Consumo y la Asociación Española de Distribuidores y Editores de Software de Entretenimiento (ADESE) realizan una campaña divulgativa del Código PEGI-Online, que se enmarca en el programa para un Internet más seguro realizado por la Unión Europea (El Correo, 2007):

.../El nuevo logotipo de PEGI-Online aparecerá en los estuches del juego si éste se vende en CD/DVD o en el propio sitio web del juego. El logotipo indicará si puede jugarse en línea y, asimismo, si ese juego o sitio en concreto es controlado por un operador que se ocupa de proteger a los jóvenes.../ 
Puntualmente, con motivo de las fiestas navideñas y los regalos consiguientes, aDeSe, intenta incentivar la publicidad, llegando a los distintos medios (La Vanguardia, 2006):

Con el propósito de informar y concienciar a los padres sobre el contenido de los videojuegos la Asociación Española de Distribuidores y Editores de Software de Entretenimiento (ADESE) distribuirá 300.000 folletos explicando el código PEGI durante las fiestas navideñas, momento elegido por los progenitores para comprar los regalos a sus hijos.

.../ recuerda Carlos Iglesias: "Por ello no escatimamos esfuerzos desde hace más de un año en seguir informando sobre el Código PEGI, unas veces suscribiendo acuerdos de colaboración como es el caso del INC y del Defensor del Menor, y otras con acciones conjuntas como la que acabamos de realizar con la Fundación Eroski.”.

Ciertamente, este acuerdo, quizás ha sido una de los más fructíferos y la empresa Eroski sigue siendo en la actualidad una de las más implicadas en publicitar estas medidas de protección (Eroski Consumer, 2008):

.../ También en smartphones: PEGI también se ha adaptado ahora a los nuevos tiempos y ofrece asesoramiento en móviles de última generación y tabletas. De este modo, se ha lanzado una aplicación tanto para iPhone e iPad, como para móviles con el sistema operativo Android. Esta permite a los padres comprobar la clasificación del videojuego que sus hijos deseen descargar en el dispositivo y saber así su conveniencia.../.

En estas últimas Navidades, Europa Press, informaba que de nuevo aDeSe ponía en marcha, por segundo año consecutivo, una campaña de divulgación en torno al Sistema PEGI. En concreto, la campaña estaba basada en la distribución de un cómic en más de 650 puntos de venta de los principales centros de distribución de videojuegos.

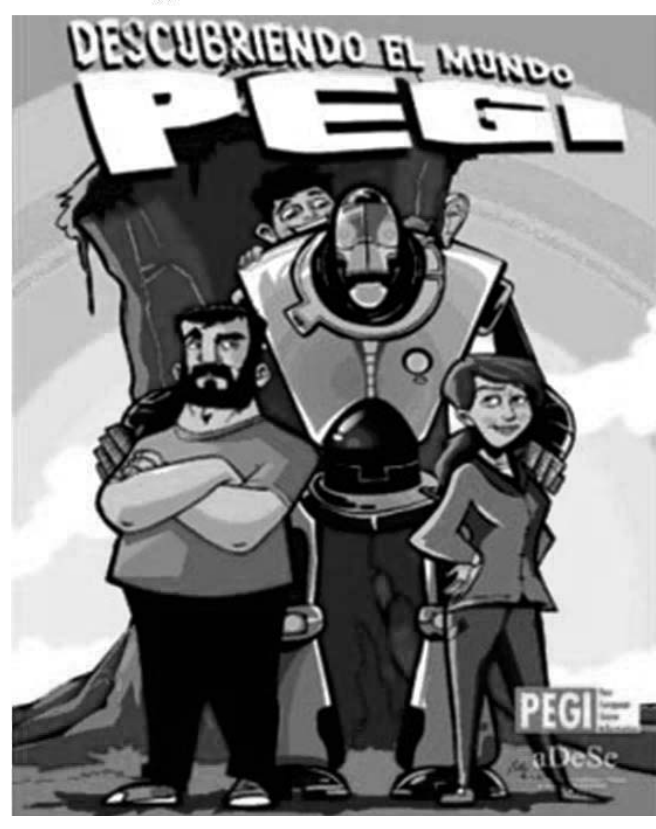

Fig. 3.: Descubriendo el mundo PEGI

El cómic cuenta por qué es importante tener en cuenta el Sistema PEGI a la hora de elegir un videojuego. Para esta iniciativa, aDeSe ha suscrito acuerdos de colaboración con Game, El Corte Inglés, Gamestop, Blade center, Peneka, Convertsoft, Zona digital, Eurovideo y Videooca en los que se distribuirán en total más de 240.000 ejemplares (aDeSe, 2011) (Fig. 3).

En suma, no solo puntualmente, sino de forma continuada y dependiendo de las noticias que van surgiendo, la prensa se hace eco de diferentes informaciones; en 2005, prueba de ello es el dossier de prensa que aDeSe publica (2004). Tan solo un año después, aDeSe se ve obligada a difundir difunde un Código de Conducta para la adquisición responsable de videojuegos, la información se difunde en diferentes medios $(A B C, 2006)$. 
Ahora bien, a pesar de todo este despliegue, desde bastantes medios e investigaciones empieza a ponerse en duda que la significación del código PEGI estuviese llegando realmente a las personas que pueden proteger al menor. Concretamente Europa Press, difunde en enero de 2007 que Amnistía Internacional exige a España una ley que regule el acceso de los niños a los videojuegos. Desde diversos medios, Esteban Beltrán, director de AI en España, insiste en que esta categorización es poco rigurosa y confusa y que el código de iconos utilizado en los envases no es suficiente para conocer el contenido del producto. Afirma que basar la protección de los menores exclusivamente en un código de libre adhesión por parte de las empresas de software de entretenimiento es una dejación de responsabilidad por parte del Estado (La Vanguardia, El Mundo, 2007).

Desde luego, no cabe duda que aunque aDeSe está haciendo lo imposible para que el código de autorregulación llegue a los usuarios, parece que no se obtiene el éxito esperado. Como ejemplo, el polémico artículo de la dramaturga Paloma Pedrero aparecido el 7 de marzo de 2009, la autora desconocía la existencia del código PEGI, y ello, unido a los adjetivos descalificadores a este tipo de ocio, provocaron un gran escándalo en la red, en la blogosfera; su efecto inmediato fue que el diario La Razón, retiró el artículo.

Evidentemente, no se trata de demonizar sin más los avances de las Nuevas Tecnologías, concretamente de los videojuegos, dado que existen múltiples investigaciones que resaltan los efectos positivos de éstos no sólo a nivel del ocio infantil, sino en aplicaciones pedagógicas y sanitarias. Lo importante es proteger al menor de aquellos que, por la temática o imágenes, puedan ser perjudiciales y para ello, los adultos deben conocer los medios de que disponemos hoy día. En este sentido, Garcia Galera en su artículo del 2006, ya se preguntaba qué conocían los padres de los videojuegos de sus hijos y exponía los resultados del estudio realizado por profesores de la Universidad Complutense de Madrid y la Universidad Carlos III de Madrid.

Más recientemente la Conferencia de Consumidores y Usuarios (CECU) e HIPACOOP han realizado un estudio para averiguar el nivel de conocimiento que tiene la población respecto a los pictogramas informativos de todo tipo de bienes de consumos, siendo el sistema empleado en los videojuegos, el PEGI, el que peores resultados ha cosechado. Tras realizar un total de 2.017 entrevistas, el estudio ha concluido que los símbolos visuales relacionados con los videojuegos son los peor identificados por los consumidores.

\section{Diseño y resultados de la investigación}

El objetivo general de nuestra investigación fue investigar los conocimientos reales que tienen los padres del código PEGI y si son conscientes de adoptar o no medidas de protección al comprar videojuegos.

\subsection{Metodología}

Se elaboró una encuesta, donde se preguntaba a padres/tutores de menores (de 11 a 16 años) diferentes cuestiones, con opciones de respuestas tanto categóricas como continuas, sobre pensamientos, creencias y control que realizan sobre la utilización de vi- 
deojuegos por parte de sus hijos. Los datos se recogieron desde enero a mayo de 2011 $\mathrm{y}$ es de resaltar que el procedimiento que se ha seguido supone la aplicación individual y personalizada de la encuesta, algo que metodológicamente la diferencia de otros estudios y aportando las garantías que se presuponen a las contestaciones cara a cara, persona a persona.

El muestreo, al azar intencionado, se realiza en distintos centros escolares, con participación voluntaria, una vez que conocen los objetivos del estudio y que los resultados del mismo serán usados exclusivamente con fines científicos. Con posterioridad a la cumplimentación de la encuesta, se les leía y explicaba en qué consistía el código PEGI, dejándoles por escrito las recomendaciones para la compra de VJs, que aconseja aDeSe.

La muestra obtenida fue de 403 progenitores, con una media de edad de 45,94 años y desviación típica de 4,8; el mínimo estaba en 34 años y el máximo en 57, con la moda en 45 años. De ellos, el $76.7 \%$ eran mujeres y el resto $(23,3 \%)$ hombres. En la tabla I, se exponen los resultados sobre la opinión que tienen los padres/tutores con respecto a los videojuegos:

Tabla I: Opinión sobre los videojuegos

\begin{tabular}{lr} 
Opciones & Porcentaje \\
\hline Partidario & 1,5 \\
Sólo de algunos & 60,5 \\
Poco partidario & 22,6 \\
No partidario & 8,0 \\
Indiferente & 7,4
\end{tabular}

Tan sólo un $1.5 \%$ son completamente partidarios, la mayoría son partidarios pero tan sólo de algunos, sin embargo, parece que estas opiniones son ignoradas a la hora de adquirir este tipo de ocio, ya que el $90 \%$ compran videojuegos a sus hijos, frente a un $10 \%$ que se niegan a hacerlo.

A continuación, en una serie de afirmaciones, daban su criterio a la hora de adquirir videojuegos, elegían del 0 al 10, en función de acuerdo o no con la afirmación, los resultados se exponen en la figura 4:

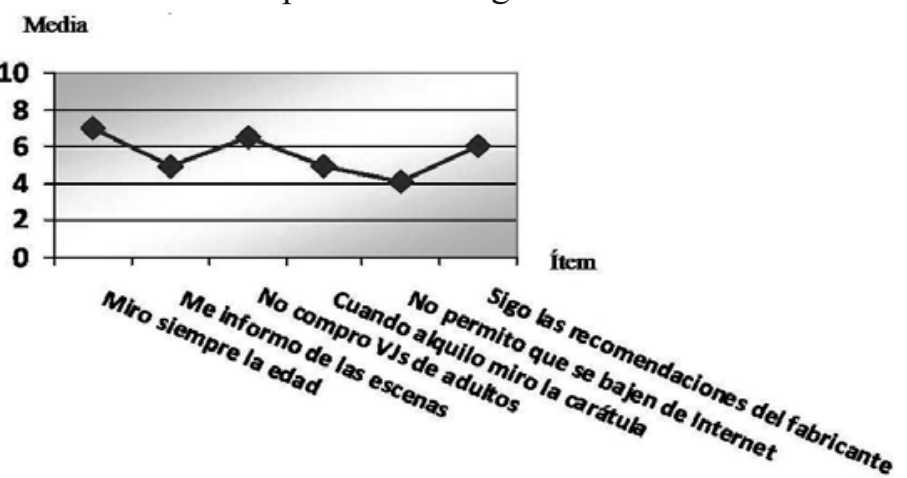

Fig. 4.: Medidas de control subjetivas

Parece que el criterio tenido más en cuenta por los padres a la hora de adquirir VJs es la edad (media $=7$ ), sin embargo, las opciones relacionadas con los contenidos (media $=4,9)$, la carátula en caso de alquiler (media $=4,9)$ y no permitir que se bajen videojuegos de internet (media $=4,07$ ), ni siquiera a nivel subjetivo alcanzaban la puntuación de aprobado.

Cuando a continuación se les pedía que indicasen las creencias personales de control ante los VJs, los resultados variaban peligrosamente. Los adultos afirmaban que prohibían VJs con escenas de discriminación racial (7); se aseguraban que no lleva- 
sen escenas sexuales (7); creen que sus hijos no han tenido problemas con los VJs $(7,6)$, reconocían que se preocupaban por los contenidos de agresividad $(7,7)$ y opinaban que los Vjs quitan tiempo de estudio (6); reconocían no manejar "esos aparatos" $(4,6)$; controlaban el tiempo de juego $(7,4)$; creen saber qué tipo de VJs tienen $(7,8)$; y lo que es más preocupante, están tranquilos cuando sus hijos juegan $(7,4)$.

Ahora bien ¿como ejercen el control? ¿saben cómo hacerlo?, para averiguarlo cuando se les preguntaba sobre el motivo central del estudio, es decir, su nivel de conocimiento sobre el código PEGI. Los datos son abrumadores, realmente como tal, y por su nombre, tan sólo lo conocen un $9,9 \%$ de los encuestados; el 90,1\% desconoce lo qué es. Este dato, se confirma cuando se les mostraban los descriptores y se les pedía que explicasen su significado. Los resultados son muy desalentadores (fig. 5):

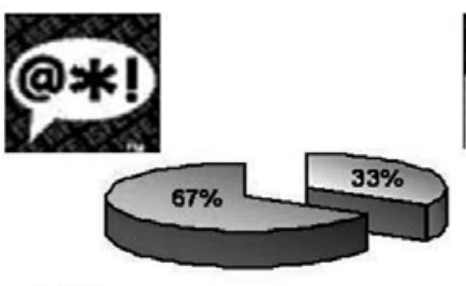

Palabras soeces
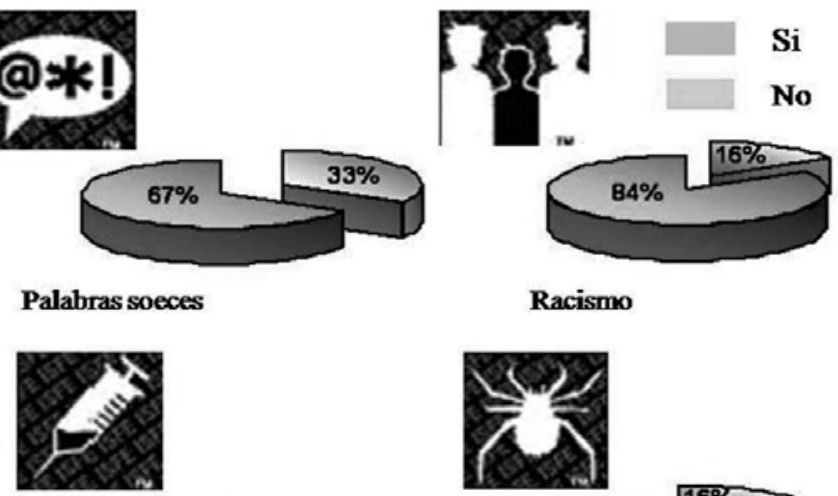

Racismo
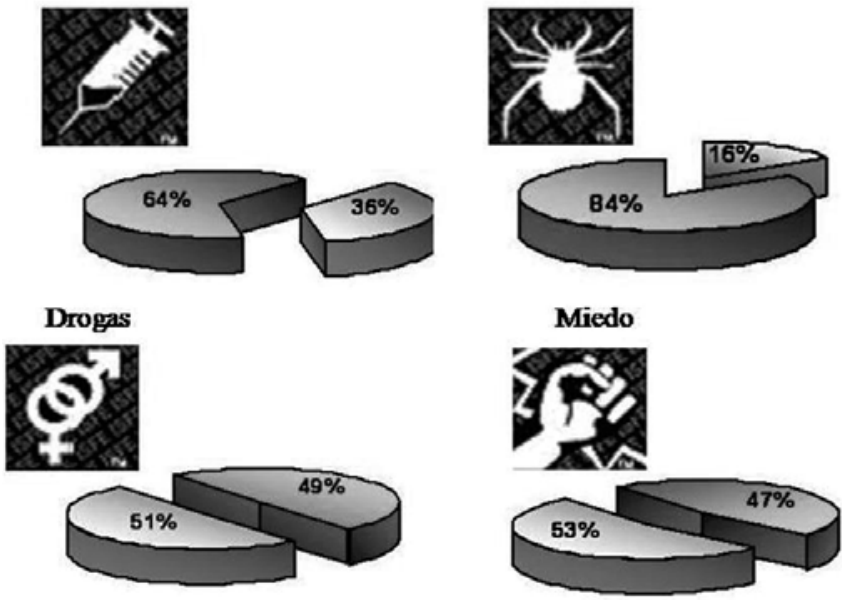

Escenas sexuales

Agresividad

Fig. 5.: Conocimiento de los descriptores PEGI

Como podemos observar en la figura 5, los símbolos mejor reconocidos son los que indican contenidos de agresividad y de escenas sexuales, pero tan solo por la mitad de los padres/tutores; un tercio identifica contenidos de drogas y palabras soeces, y son los relacionados con el miedo y el racismo los peor identificados.

Los resultados ponen de manifiesto que a padres y/o tutores no les llega correctamente la información, detectan la edad, pero no saben que está en relación con los 
descriptores, y ni siquiera identifican que la araña indica escenas de miedo, o que tres contornos de imágenes, dos blancas y una negra advierte que el VJ contiene escenas de racismo; cuestión ésta que si analizamos desde un punto de vista gráfico, tampoco es de extrañar.

Este hecho, ya denunciado en los medios de comunicación, podría deberse, bien a que los símbolos no sean los adecuados, bien a que los usuarios no interpretan la imagen, pero cuando leemos que se han impreso 250.000 folletos informativos repartidos en 800 centros de 14 grandes superficies comerciales de toda España, pensamos... este indudable esfuerzo ¿no será una gota de agua en un océano demasiado extenso? Incluso sabiendo que los descriptores siguen sin identificarse, se nos ocurre ¿por qué no se explicitan con lenguaje escrito debajo del símbolo?, es decir, porqué no se incluye explícitamente frases como: "contiene escenas de miedo"; "contiene palabrotas"; "contiene escenas relacionadas con las drogas"; "contiene escenas sexuales"; "contiene escenas de violencia", y/o "iprecaución! se puede jugar online".

Estamos de acuerdo con García Galera en afirmar que la realidad deja constancia del desconocimiento de los padres sobre las medidas de control de los videojuegos y esta evidencia aconseja una mayor atención hacia aquellos cuyos contenidos sean inadecuados para los más pequeños, por ello, desde distintos foros, se insta a los padres a que compartan con sus hijos, no sólo los videojuegos sino el tiempo de ocio, reflexionando de manera conjunta sobre las diferentes temáticas. Conviene insistir a los responsables, sobre la conveniencia de informar no sólo en los puntos de venta de forma muy visible, sino en los centros escolares, con charlas y notificaciones al respecto, y como no, mediante los medios de comunicación, sobre todo en la televisión (Llorca, 2009).

\section{Referencias bibliográficas}

ABC (2004): “Un acuerdo promoverá el nuevo etiquetado de videojuegos". http://hemeroteca.abc.es/nav/Navigate.exe/hemeroteca/madrid/abc/2004 [Consultado: 24 de mayo de 2012]

ABC (2006): "Código de Conducta para la adquisición responsable de videojuegos". http://www.abc.es/hemeroteca/historico-21-12-2006/abc/Sociedad [Consultado: 24 de mayo de 2012]

ANTENA 3 (2010): "El Código Pegi fomenta el consumo responsable de videojuegos". www.antena3.com/viveconectado/actualidad/-noticias-vive-conectado [Consultado: 26 de mayo de 2012]

ASOCIACIÓN CASTELLANO-LEONESA DE CONSUMIDORES Y USUARIOS (CECU): "Guía de Pictogramas". http://www.cecucyl.org [Consultado: 22 de mayo de 2012]

ASOCIACIÓN ESPAÑOLA DE DISTRIBUIDORES Y EDITORES DE SOFTWARE (aDeSe) (2001): "Los videojuegos en España". www.adese.es/web/informe [Consultado: 20 de octubre de 2003]

ASOCIACIÓN ESPAÑOLA DE DISTRIBUIDORES Y EDITORES DE SOFTWARE DE ENTRETENIMIENTO (aDeSe) (2006): “Código de Conducta aDeSe 
para la adquisición responsable de videojuegos". www.abc.es/hemeroteca/historico-21-12-2006/abc [Consultado: 22 de mayo de 2012]

ASOCIACIÓN ESPAÑOLA DE DISTRIBUIDORES Y EDITORES DE SOFTWARE DE ENTRETENIMIENTO (aDeSe) (2010): "Mejorar la reputación social y relevancia industrial de los videojuegos en el mercado español a través del sistema PEGI". www.evercom.es/ [Consultado: 20 de mayo de 2012]

ASOCIACIÓN ESPAÑOLA DE DISTRIBUIDORES Y EDITORES DE SOFTWARE DE ENTRETENIMIENTO (aDeSe) (2006): www.adese.es/pdf/comiccompleto [Consultado: 29 de mayo de 2012]

AVELLANEDA, Elena (2003): "El videojuego se protege de la censura con códigos éticos de autorregulación". www.elpais.com/diario/2003/09/11/ciberpais [Consultado: 25 de mayo de 2012]

CONFERENCIA DE CONSUMIDORES Y USUARIOS (CECU) e HIPACOOP (s/f): "Los usuarios desconocen el significado de los pictogramas del código PEGI". www.3djuegos.com/noticias-ver/ [Consultado: 26 de mayo de 2012]

EL CORREO (2007): "Videojuegos aptos para tus hijos". www.salud.elcorreo.com /consejos-sanos/diciembre07/ [Consultado: 6 de noviembre de 2012]

EL MUNDO (2007): “Amnistía pide un marco legal que proteja a los niños de los videojuegos". www.elmundo.es/navegante/2007/01/04/tecnologia [Consultado: 22 de abril de 2012]

EL PAÍS. (2005). "La industria española de videojuegos refuerza su código de conducta". www.tecnologia.elpais.com/tecnologia/2005/07/29/actualidad/ [Consultado: 26 de mayo de 2012]

EROSKI CONSUMER (2008): "Código PEGI: saber qué videojuegos son recomendables". www.consumer.es/web/es/tecnologia/software/2008/ [Consultado: 24 de mayo de 2012]

ESTÉVEZ, César (2012): "El Código Pegi fomenta el consumo responsable de videojuegos". www.antena3.com/viveconectado/actualidad [Consultado: 24 de mayo de 2012]

EUROPA PRESS (2011): www.europapress.es/portaltic/videojuegos/ [Consultado: 22 de mayo de 2012].

GARCÍA GALERA, Ma del Carmen (2006): "Proteger a la infancia. Los Códigos de Autorregulación a debate". Revista de Comunicación y Nuevas Tecnologías, 7, 119.

INSTITUTO NACIONAL DEL CONSUMO (INC) (2007): "Campaña divulgativa del Código PEGI-Online". www.msc.es/gabinete/notasPrensa [Consultado: 24 de mayo de 2012]

LA VANGUARDIA (2006): "Consumo lanza una campaña para orientar a los padres en la elección devideojuegos" www.lavanguardia.com/internet [Consultado: 29 de octubre de 2012] 
LA VANGUARDIA (2007):" Amnistía Internacional pide un marco legal para proteger a los menores en el mercado de los videojuegos". www.lavanguardia.mobi /slowdevice/noticia [Consultado: 22 de abril de 2012]

LLORCA, Ángeles (2009): Hábitos y usos de los videojuegos en la comunicación visual: Influencia en la inteligencia espacial y el rendimiento escolar. Tesis Doctoral. Granada, Universidad de Granada, Departamento de Didáctica de la Expresión Musical, Plástica y Corporal.

MINISTERIO DE SANIDAD, SERVICIOS SOCIALES E IGUALDAD (2003): "España adopta un nuevo código europeo de autorregulación para los videojuegos". www.consumo-inc.gob.es/noticias/Notasdeprensa/2003 [Consultado: 24 de mayo de 2012]

\section{Dra. Ma Ángeles DíEZ SÁNCHEZ}

Universidad de Salamanca

Facultad de Medicina. Área de Psiquiatría

Profesora Titular

madiez@usal.es

\section{Dra. Ángeles LLORCA DÍEZ}

Universidad de Salamanca

Facultad de Medicina.

Periodista. Colaboradora de investigación

tanamanca@hotmail.com

\section{Dra. Gloria María BUENO CARRERA}

Universidad de Salamanca

Facultad de Medicina. Área de Psiquiatría

Profesora Asociada.

gloriabueno@usal.es

\section{Beatriz CABREJAS MARTÍNEZ}

Universidad de Salamanca

Facultad de Medicina. Área de Psiquiatría

Colaboradora de investigación

cmbea79@usal.es

\section{Teresa GALLEGO HERNÁNDEZ}

Universidad de Salamanca

Facultad de Medicina. Área de Psiquiatría

Colaboradora de investigación

gallego.tr@usal.es 